\title{
Days out of role due to common physical and mental conditions in Portugal: results from the WHO World Mental Health Survey
}

Graça Cardoso, Miguel Xavier, Gemma Vilagut, Maria Petukhova, Jordi Alonso, Ronald C. Kessler and José Miguel Caldas-de-Almeida

\section{Background}

One important aspect of the societal burden of mental disorders is the extent to which these problems cause disability.

\section{Aims}

To assess days out of role associated with commonly occurring mental disorders in comparison with physical disorders in Portugal.

\section{Method}

National cross-sectional survey, with home interviews carried out with 3849 adult (aged $18+$ ) respondents (57.3\% response rate).

\section{Results}

Twelve-month prevalence for any mental disorder was $21.8 \%$, any physical disorder $55.1 \%$ and any disorder $63.1 \%$, with an average of 2.3 disorders per respondent with a disorder. Close to one out of every 10 respondents (9.2\%) reported at least one day totally out of role in the past month (median of 6.4 days/any). The 18 conditions accounted for $78.2 \%$ of all days out of role, with $20.2 \%$ because of mental disorders and $59.2 \%$ because of physical disorders.

\section{Conclusions}

Mental disorders account for a substantial proportion of all role disability in the Portuguese population. Early detection and intervention would have a positive societal effect. Owing to highly frequent comorbidity, simultaneous management of mental and physical disorder comorbidities is advised for greater effect.

\section{Declaration of interest}

R.C.K. in the past 3 years has been a consultant for Hoffmann-La Roche Inc., Johnson \& Johnson's Wellness and Prevention, Inc. and Sanofi-Aventis Groupe. He has served on advisory boards for Mensante Corporation, Johnson \& Johnson Services, Inc., Lake Nona Life Project and U.S. Preventive Medicine, Inc. He is a co-owner of DataStat, Inc.

\section{Copyright and usage}

(c) The Royal College of Psychiatrists 2017. This is an open access article distributed under the terms of the Creative Commons Non-Commercial, No Derivatives (CC BY-NC-ND) license.
Scientific evidence has shown that mental disorders are associated with high levels of role disability in terms of both decreased role performance (presenteeism) and total loss of productivity (days out of role (DOR)). These costs are substantial, ${ }^{1,2}$ with the annual costs of DOR in the USA estimated at 3.6 billion dollars ${ }^{3}$ and the indirect costs of brain disorders associated with patients' productivity losses across 30 European countries estimated at 315.1 billion euros in $2010 .{ }^{4}$ But there is a need for more accurate data at the national level on the impact of specific mental disorders on DOR, as well as comparisons with common physical disorders and the effects of comorbidities among these disorders, to make rational resource allocation decisions for targeted interventions aimed at preventing and reducing these impairments. Although a small number of reports exist that address these issues, they are either limited to the USA ${ }^{3,5}$ or apply to the world overall. ${ }^{6}$

The World Mental Health (WMH) initiative (www.hcp.med. harvard.edu/WMH) was launched by the WHO with the purpose of carrying out general population surveys in countries throughout the world to assess the prevalence and correlates of mental disorders. ${ }^{7}$ One part of the WMH interview assesses the presence of commonly occurring chronic physical disorders to facilitate analysis of the comparative burdens of common mental and physical disorders on role functioning. Comparative analyses of the WMH data show that Portugal has the second highest prevalence of mental disorders in Europe (next to Northern Ireland) ${ }^{8,9}$ and a high rate compared with other WMH countries throughout the world. ${ }^{10}$

As the Portuguese national health system is state funded, covers the entire population and gives primary care services an important role in detecting and treating both physical and mental disorders, country-level data for Portugal on the comparative burdens of common mental disorders could be valuable to health policy planners in directing enhanced screening and treatment quality improvement efforts. Based on this realisation, analysis of the Portuguese WMH Survey was carried out to provide this type of information in parallel to data previously in the aggregate for all $24 \mathrm{WMH}$ countries $^{6}$ on the relative effects of common mental disorders on DOR and comparisons with physical disorders. A novel method is used to estimate these effects in such a way as to adjust for comorbidity.

\section{Method}

\section{Sample}

Portugal is a Southern European country classified by the World Bank $^{11}$ as a higher income country. Its territory consists of a continental main area and the Madeira and Azores islands, both in the Atlantic Ocean. According to the last census, Portugal's population is 10.5 million inhabitants. ${ }^{12}$ A stratified multistage clustered area probability sample of Portuguese household residents, 18 years of age or above, nationally representative from the mainland was used to select a household sample for the Portugal WMH Survey. The methods and procedures have been described elsewhere. ${ }^{7,13-15}$ All interviews were administered face-to-face by trained lay interviewers using training and field quality control procedures described elsewhere. ${ }^{13,16}$ Interviews were carried out in 2008-2009. Informed consent was obtained before beginning the interviews using procedures approved by the Ethics Committee of 
the NOVA Medical School/Faculdade de Ciências Médicas, the institution coordinating the survey. The response rate, calculated as the ratio of the number of households in which an interview was completed to the number of households originally sampled, excluding from the denominator households known not to be eligible either because of being vacant at the time of initial contact or because the residents were unable to speak the designated languages of the survey, was $57.3 \%$.

Each interview had two parts. Part I, which was administered to all respondents $(n=3849)$, contained assessments of core mental disorders. All Part I respondents who met criteria for any of these disorders plus a probability subsample of other Part I respondents were administered Part II, which assessed correlates and disorders of secondary interest to the study. The assessment of physical disorders was included in Part II, and consequently the focus of this paper. The Part II data were weighted to adjust for the under-sampling of Part I respondents who did not have any core disorders and to adjust for residual discrepancies between sample and population distributions on a range of sociodemographic and geographic variables, making the weighted Part II sample equivalent to the Part I sample in terms of prevalence of core disorders and equivalent to the population in terms of the sociodemographic and geographic variables used for population weighting. There were 2060 respondents in the Part II sample, which is the sample used in this report. All analyses are based on Part II weights that allow results to be extrapolated to the total population.

\section{Measurement}

\section{Mental disorders}

Mental disorders were assessed with Version 3.0 of the WHO Composite International Diagnostic Interview (CIDI), a fully structured lay-administered interview designed to generate research diagnoses of common mental disorders according to the definitions and criteria of both the DSM-IV and ICD-10 diagnostic systems. ${ }^{7}$ The eight mental disorders considered in this report include mood disorders (major depressive disorder, bipolar I-II disorder), anxiety disorders (panic disorder and/or agoraphobia, specific phobia, social phobia, generalised anxiety disorder (GAD), post-traumatic stress disorder (PTSD)) and alcohol abuse (with and without dependence). Only disorders present in the 12 months before interview were considered. DSM-IV criteria were used in generating diagnoses. A clinical reappraisal study with blinded clinical follow-up interviews using the Structured Clinical Interview for DSM-IV (SCID) ${ }^{17}$ in several WMH Surveys (France, Italy, Spain, US) found generally good concordance between diagnoses based on the CIDI and those based on the SCID. ${ }^{18}$

\section{Chronic physical disorders}

Physical disorders were assessed with a standard chronic disorders checklist. Checklists of this sort have been shown to yield more complete and accurate reports of disorder prevalence than estimates derived from responses to open-ended questions. ${ }^{19,20}$ Reports based on such checklists have also been shown in previous methodological studies to have moderate to good concordance with medical records, ${ }^{21,22}$ although it is noteworthy that higher reports are generally obtained in self-reports than medical records of symptom-based disorders because substantial proportions of people with these disorders fail to seek treatment for many of these disorders.

The 10 disorders considered here are as follows: arthritis, cancer, cardiovascular disorders (heart attack, heart disease, hypertension, stroke), chronic pain disorders (chronic back or neck pain, other chronic pain), diabetes, migraines or other frequent or severe headaches, insomnia, neurological disorders (multiple sclerosis,
Parkinson's disease, epilepsy or seizures), digestive disorders (stomach or intestinal ulcers, irritable bowel disorder) and respiratory disorders (seasonal allergies, asthma, chronic obstructive pulmonary disease, emphysema). The symptom-based disorders in this set (i.e. arthritis, pain disorders, heart attack, stroke) were assessed with respondent reports as to whether or not they ever experienced the disorder, whereas the silent remaining disorders were assessed with respondent reports of whether or not a doctor or other health professional ever told them they had the disorder. Questions about persistence were asked about lifetime disorders that can remit. The focus in this report is on disorders present in the 12 months before interview.

\section{Days out of role}

A modified version ${ }^{23}$ of the WHO Disability Assessment Schedule ${ }^{24}$ was used to ask respondents the number of days in the 30 days before interview (i.e. beginning yesterday and going back 30 days) that they were totally unable to work or carry out their normal activities because of problems with either their physical health, their mental health or their use of alcohol or drugs. Good concordance of such reports of DOR for a 30-day recall period has been documented both with payroll records of employed people $^{25,26}$ and with prospective daily diary reports. ${ }^{27}$

\section{Statistical analysis}

Multiple regression analysis was used to examine the associations of the physical and mental disorder assessed in the survey with reported DOR in the past 30 days, controlling for age, gender, employment status and education. Employment status was operationalised as a three-category variable distinguishing respondents who were employed, retired, or in other employment status (including unemployed, disabled, student, homemaker or other) at the time of the interview. Given the substantial comorbidity among the disorders, ${ }^{28}$ we included additional interaction terms in the model to account for the possibility that the association of a given disorder with DOR varies depending on the presence or absence of other disorders. However, given that the logically possible number of interactions among comorbid disorders was higher than the number of respondents in the survey, some a priori structure had to be imposed on the data to allow these models to be estimated. This was done by a non-linear regression approach implemented in previous cross-national WMH analyses of the associations of comorbid disorders with DOR. ${ }^{29}$ In brief, the approach collapsed interactions by assuming that the association of any one disorder with DOR is modified by a composite comorbidity profile defined by the sum of the regression coefficients of the other disorders experienced by the respondent. In other words, the model includes a separate term for each disorder considered in addition to an interaction term for each of these disorders with a composite variable that is made up by summing the main effect regression coefficients of all disorders the respondent has. Given that the coefficients in the interaction term vary depending on the values of the main effects, inherently non-linear regression analysis was needed to estimate model coefficients. ${ }^{30}$ We used a SAS macro $^{31}$ developed by staff of the WMH Data Analysis Coordination Center to carry out the simulation needed to estimate this model with iterative procedures. ${ }^{32}$

A generalised linear model (GLM) ${ }^{33}$ with a log link function and variance proportional to the mean (a Poisson model) was used to estimate the multivariate associations of disorders with DOR. This specification was used to address the fact that the outcome variable was highly skewed, with a considerable proportion of individuals reporting no disability. This model specification was selected over six other GLM alternatives based on standard 
diagnostic procedures to compare model fit. ${ }^{34}$ An SAS macro written by staff from the WMH data analysis centre was used to estimate design-based standard errors of parameter estimates using the jackknife repeated replications simulation method. ${ }^{35}$

As the prediction equation includes interaction terms, the predictive association of each disorder is distributed across a number of different coefficients. Simulation based on model coefficients was used to summarise all these components effects into a single term by estimating the predicted value of the outcome for each respondent from the coefficients in the final model and 18 disorder-specific simulated predicted estimates applying the same model coefficients but assuming that one particular disorder at a time was no longer present (i.e. setting the coefficients associated with that disorder to zero and modifying the summary comorbidity score accordingly). Individual-level incremental associations of each disorder with the outcome were then calculated as the difference between the simulated predicted estimate for that particular disorder divided by the number of respondents with the disorder in question. The individual-level association is interpreted as the net association of the disorder with DOR in terms of mean additional DOR experienced by individuals having that disorder.

We calculated the population attributable risk proportion (PARP) to describe the societal-level association of each disorder with DOR. PARP is a widely used descriptive measure in the epidemiological literature ${ }^{36}$ that is obtained by multiplying the individual-level estimates described in the last paragraph by the prevalence of the disorder and projecting to some convenient time period (in this case, a 12-month period). For example, if the average person with a given disorder had 1.5 more DOR than other sociodemographically comparable people in the population net of comorbidities and the prevalence of that disorder was $3 \%$, then there would be 4.5 (i.e. $1.5 \times 3 \% \times 100$ ) additional DOR in the past 30 days for all people in the population and 54 days per 100 people in the population in the course of 12 months. Note that the estimated standard error of PARP was inflated proportional to the estimated individual-level coefficient in moving from the 30 -day to 12 -month time frames. That is, assuming the standard error of the individual-level 1.5 DOR/ 30-day estimate was 0.3 , then the estimated standard error of PARP would be 18.0 (i.e. $0.5 \times 3 \% \times 100 \times 12$ ), which has the same ratio relative to the estimate of PARP (i.e. $54 / 18=3.0$ ) as each individual-level estimate has to its standard error (i.e. $1.5 / 0.5=3.0$ ).

The same procedures were used to calculate individual-level and population-level associations of any physical disorder, any mental disorder and any disorder with DOR. Significance tests were consistently evaluated by 0.05 -level, two-sided design-based tests. Analyses were performed with SAS software, version 9.3 (SAS Institute, Cary, North Carolina, USA) and SUDAAN software, version 9 (SAS codes are available upon request).

\section{Results}

\section{The distribution of DOR}

Sample characteristics, shown in Table 1, include a mean age of 46.5 years, a somewhat higher proportion of women (51.9\%) than men, and the majority of the population (54.8\%) having at least high school education. Those 65 or older were $18.8 \%$ of the sample, with a higher proportion of $65+$ among women $(20.1 \%)$ than men (16.5\%) (not shown). Also shown are the sample characteristics of the other WMH groups of countries.

The mean number of health-related DOR in the month prior to the interview was 1.2 in the total Portuguese sample, which is the equivalent of 144 DOR per year per 100 people in the population (Table 2). This mean includes $9.2 \%$ of respondents who reported any DOR with a mean of 12.9 DOR in the last month among those with any such days. The distribution is skewed to the right, as indicated by the median (6.4 days) being lower than the mean among those with any DOR in the total sample. Inspection of the collapsed distribution of DOR among respondents with any such days shows that roughly one-third of such individuals had 1-2 such days, another one-third had 3-20 days and the final one-third had 21 or more such days in the past 30 days, with roughly equal numbers of people in the intermediate category having $3-5,6-10$ and 11-20 DOR. This distribution is skewed downwards, in comparison, among respondents younger than 65 and upwards among those 65 or older.

\section{Disorder prevalence estimates}

More than half $(63.1 \%)$ of respondents in Portugal reported one or more of the disorders considered here (Table 3 ). The proportion that reported at least one physical disorder (55.1\%) is considerably higher than the proportion that reported any mental disorder $(21.8 \%)$. The rank order of prevalence estimates across disorders shows that cardiovascular disorders have the highest prevalence $(24.5 \%)$, followed by arthritis $(18.8 \%)$ and respiratory disorders (14.8\%). Among mental disorders, specific phobia is the most commonly reported (10.2\%), followed by major depression $(7.8 \%)$. Other highly prevalent disorders were chronic pain disorders (13.6\%) and headache/migraine (10.0\%).

Respondents who reported any disorder had an average of 2.3 disorders (detailed results available on request). Comorbidity was the norm, with $64.2 \%$ of the respondents with at least one disorder reporting at least two. Odds ratios (ORs) between pairs of disorders were largely positive $(81.7 \%$ of all the $19 \times 18 / 2=125$ ORs between pairs of disorders) and significant $(43.1 \%$ of all ORs were significant at the 0.05 level). The ORs were higher (median and interquartile range) among pairs of comorbid physical disorders $(2.3,1.6-2.7)$ and comorbid mental disorders $(5.0,3.2-6.9)$ than between pairs of comorbid physical-mental disorders (1.3, 0.9-2.0) (data available as supplemental materials).

\begin{tabular}{|c|c|c|c|c|c|c|}
\hline & $N$ & $\begin{array}{c}\text { Age } \\
\text { Mean (s.e.) }\end{array}$ & $\begin{array}{l}\text { Females } \\
\% \text { (s.e.) }\end{array}$ & $\begin{array}{c}\text { Not married } \\
\% \text { (s.e.) }\end{array}$ & $\begin{array}{c}\text { High school or more } \\
\% \text { (s.e.) }\end{array}$ & $\begin{array}{c}\text { Not working } \\
\% \text { (s.e.) }\end{array}$ \\
\hline Portugal & 2060 & $46.5(0.6)$ & $51.9(1.5)$ & $30.4(1.4)$ & $54.8(1.7)$ & $40.3(1.5)$ \\
\hline All countries & 62971 & $42.2(0.1)$ & $51.9(0.3)$ & $36.6(0.3)$ & $57.4(0.3)$ & $42.0(0.3)$ \\
\hline Comparison among countries & & $183.8(<0.0001)^{\mathrm{a}}$ & $1.2(0.2)$ & $20.3(<0.0001)^{b}$ & $165.7(<0.0001)^{\mathrm{b}}$ & $74.4(<0.0001)^{\mathrm{b}}$ \\
\hline Lower income & 16051 & $37.0(0.2)$ & $51.1(0.6)$ & $37.8(0.6)$ & $47.2(0.6)$ & $41.8(0.6)$ \\
\hline Middle income & 14811 & $40.3(0.2)$ & $52.5(0.6)$ & $38.0(0.6)$ & $44.5(0.6)$ & $51.8(0.6)$ \\
\hline Higher income & 32109 & $45.7(0.2)$ & $52.1(0.4)$ & $35.2(0.4)$ & $69.1(0.4)$ & $37.5(0.4)$ \\
\hline Comparison lower, middle, higher & & $655.5(<0.0001)^{\mathrm{a}}$ & $1.8(0.2)$ & $10.4(<0.0001)^{\mathrm{b}}$ & $638.6(<0.0001)^{b}$ & $177.6(<0.0001)^{\mathrm{b}}$ \\
\hline
\end{tabular}




\begin{tabular}{|c|c|c|c|c|c|c|}
\hline & Total population \% & s.e. & Population<65 \% & s.e. & Population $\geq 65 \%$ & s.e. \\
\hline Any days out of role & 9.2 & 0.7 & 8.0 & 0.7 & 14.6 & 2.5 \\
\hline 1 day & 16.6 & 2.9 & 23.4 & 4.3 & 0 & \\
\hline 2 days & 17.7 & 3.7 & 20.6 & 4.7 & 10.7 & 4.1 \\
\hline $3-5$ days & 11.6 & 2.5 & 12.8 & 2.7 & 8.5 & 5.1 \\
\hline 6-10 days & 10.4 & 2.1 & 6.9 & 1.8 & 19.0 & 5.9 \\
\hline 11-20 days & 12.5 & 3.0 & 5.8 & 1.9 & 28.6 & 8.3 \\
\hline \multirow[t]{2}{*}{ 21-30 days } & 31.2 & 5.3 & 30.5 & 5.9 & 33.1 & 9.6 \\
\hline & Mean/median & s.e. & Mean/median & s.e. & Mean/median & s.e. \\
\hline $\begin{array}{l}\text { Mean days out of role per } \\
\text { month (all respondents) }\end{array}$ & 1.2 & 0.2 & 0.9 & 0.2 & 2.4 & 0.6 \\
\hline $\begin{array}{l}\text { Mean days out of role per } \\
\text { month (respondents } \\
\text { with any day out of role) }\end{array}$ & 12.9 & 1.4 & 11.5 & 1.7 & 16.3 & 1.9 \\
\hline $\begin{array}{l}\text { Median days out of role per } \\
\text { month (respondents } \\
\text { with any day out of role) }\end{array}$ & 6.4 & 2.7 & 2.9 & 1.9 & 14.4 & 2.0 \\
\hline
\end{tabular}

Mean DOR per month varied by disorder (Table 3 ). The highest mean numbers of DOR were found in individuals with digestive disorders (5.5), PTSD (5.4) and bipolar disorders (5.3). Individuals with any disorder had an average of 1.8 more DOR in a month (1.9 days for those with any mental disorder and 2.0 for those with any physical disorder) compared with those with no disorders.

Table 4 shows the additional DOR per month among respondents with a disorder (individual-level effect) adjusting by age, gender, marital status and employment, as well as the number and type of comorbid disorders. In Portugal, the most disabling disorders were PTSD (3.2 additional days), digestive disorders (3.1) and bipolar disorders (2.8). Also in Table 4, the PARP of DOR for each disorder is presented. Cardiovascular disorders contributed with the highest proportion ( $30 \%$ on average), followed by digestive disorders (9.5\%), PTSD and arthritis (8.7\% each) and chronic pain $(6.6 \%)$.

Individual effects projected to the year (12 months) and PARPs in the Portuguese sample are presented in Fig. 1. The figure clearly shows that the majority of the most impacting disorders according to their individual-level effect - most notably PTSD, digestive disorders, bipolar disorders, cancer and cardiovascular disorders - (Fig. 1A) are quite different from those that have the most impact at the societal level - cardiovascular disorders, digestive disorders, PTSD, arthritis and chronic pain (Fig. 1B) because of differences in prevalence across disorders. However, PTSD and digestive and cardiovascular disorders show a high simultaneous individual-level and societal-level effect.

\begin{tabular}{|c|c|c|c|c|c|c|}
\hline Disorder & Prevalence (\%) & s.e.\% & Number of people with any DOR & Mean DOR & s.e. Mean & Median* (Cl) \\
\hline Any disorder & 63.1 & 1.6 & 207 & 1.8 & 0.3 & $10.0(4.8,15.3)$ \\
\hline Any mental disorder & 21.8 & 0.9 & 119 & 1.9 & 0.3 & $5.8(2.5,9.0)$ \\
\hline Alcohol abuse & 1.6 & 0.3 & 5 & 0.9 & 0.6 & $2.8(2.0,7.2)$ \\
\hline Bipolar & 0.9 & 0.2 & 11 & 5.3 & 2.2 & $17.5(6.6,28.5)$ \\
\hline Depression & 7.8 & 0.5 & 54 & 2.1 & 0.3 & $2.8(1.5,11.4)$ \\
\hline GAD & 2.2 & 0.3 & 22 & 4.5 & 1.4 & $21.3(10.0,30.0)$ \\
\hline Panic disorder & 1.7 & 0.3 & 14 & 3.4 & 1.5 & $15.1(5.3,24.8)$ \\
\hline PTSD & 2.3 & 0.3 & 20 & 5.4 & 1.5 & $16.4(7.2,25.6)$ \\
\hline Specific phobia & 10.2 & 0.8 & 51 & 1.3 & 0.3 & $2.5(0,5.3)$ \\
\hline Social phobia & 3.2 & 0.3 & 19 & 2.2 & 0.7 & $8.8(0,18.1)$ \\
\hline Any physical disorder & 55.1 & 1.6 & 178 & 2.0 & 0.3 & $13.4(8.3,18.4)$ \\
\hline Arthritis & 18.8 & 1.2 & 79 & 2.7 & 0.5 & $14.5(9.7,19.2)$ \\
\hline Cancer & 2.7 & 0.4 & 19 & 4.0 & 1.1 & $13(2.5,23.4)$ \\
\hline Cardiovascular & 24.5 & 1.4 & 80 & 2.8 & 0.6 & $20.5(10.9,30.0)$ \\
\hline Diabetes & 5.8 & 0.6 & 21 & 3.2 & 1.4 & $22.3(10.9,30.0)$ \\
\hline Digestive & 3.3 & 0.6 & 27 & 5.5 & 1.6 & $12.9(5.3,20.5)$ \\
\hline Headache or migraine & 10.0 & 0.8 & 55 & 2.3 & 0.7 & $3.7(0,7.7)$ \\
\hline Insomnia & 6.0 & 0.6 & 36 & 2.6 & 0.9 & $5.9(0,12.3)$ \\
\hline Neurological & 1.5 & 0.3 & 9 & 2.6 & 1.1 & $5.5(0.8,12.0)$ \\
\hline Pain & 13.6 & 0.9 & 69 & 3.5 & 0.7 & $11.9(3.3,20.5)$ \\
\hline Respiratory & 14.8 & 1.2 & 48 & 1.1 & 0.2 & $4.1(0,9.4)$ \\
\hline $\begin{array}{l}\text { Respondents with positive } \\
\text { days out of role }\end{array}$ & & & 241 & 13.1 & 1.4 & \\
\hline All respondents & & & & 1.2 & 0.2 & \\
\hline $\begin{array}{l}\text { Respondents with positive } \\
\text { days out of role (median) }\end{array}$ & & & & 6.5 & 2.8 & \\
\hline
\end{tabular}




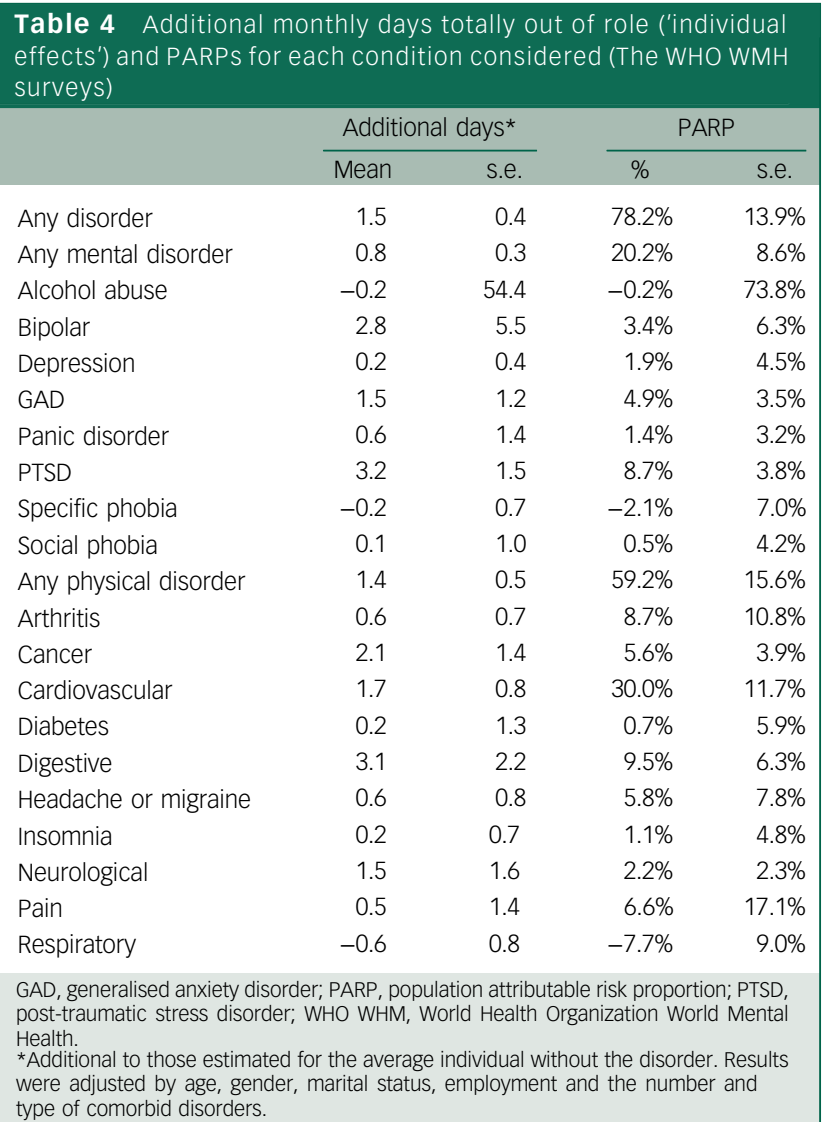

\section{Discussion}

Interpretation of results should be made with a number of limitations in mind. First, the analysis only included a restricted set of the most common physical and mental disorders, some of which were pooled to form larger disorder groups. Some burdensome disorders, such as dementia, drug abuse and psychosis, were not included, but the ones that were included are among those most commonly reported in previous population studies. ${ }^{3}$ Second, selfreports were used to assess these disorders. Self-reports of chronic disorders such as diabetes, heart disease and asthma have shown reasonable concordance with general practitioner records in previous methodological studies. ${ }^{37}$ However, some bias might exist that accounts for the generally higher prevalence estimates of these disorders in developed compared with less developed countries, ${ }^{6}$ as could be the case in the Portuguese sample. Third, we only considered the days reported by the respondents as those when they were totally unable to do their work or usual activities. We did not consider days with reduced role performance (which is generally referred to in the literature as presenteeism). ${ }^{37}$ This means that our analysis underestimates the productivity loss due to the disorders considered here. Fourth, as in the remaining countries' surveys, we assessed DOR in the 30 days prior to the interview and then projected the numbers in this recall interval to the whole year rather than asking directly about the past year in an effort to reduce recall error of self-reports and to increase comparability with previous reports. ${ }^{3}$ In the case of more episodic disorders, though, this restricted recall period might have missed a severe exacerbation present in the previous year but not in the month before the interview, leading to mismatch between estimates of severity and prevalence. However, the large number of events assessed presumably reduced the extent to which this mismatch occurred. Fifth, the response rate was relatively low, although similar to the rates in
(A)

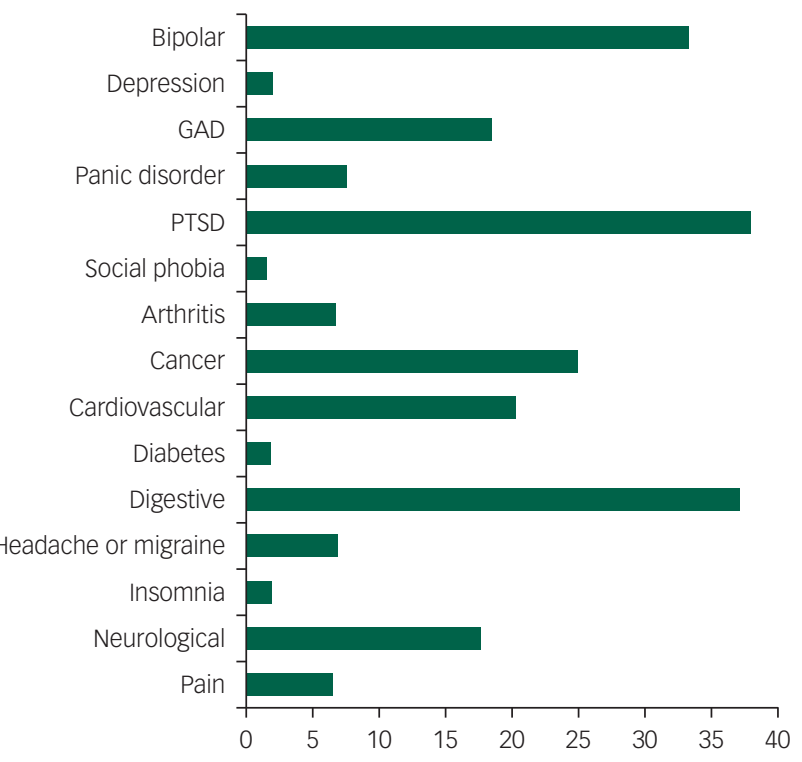

(B)

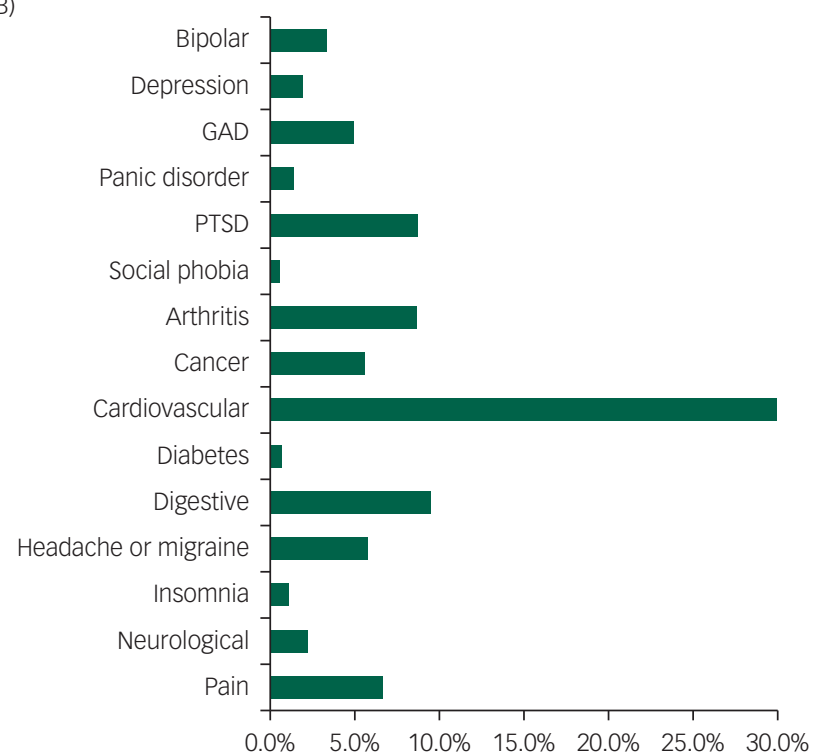

Fig. 1 Yearly days totally out of role due to each of the 18 health conditions considered: (A) among those suffering the condition ('individual effect') and (B) population attributable risk proportion (PARPS) (World Health Organization World Mental Health Surveys). GAD, generalised anxiety disorder; PTSD, post-traumatic stress disorder.

other high-income European countries that participated in the WMH Surveys (France 45.9\%, Belgium 50.6\%, The Netherlands $56.4 \%$, Germany $57.6 \%$, Italy $71.3 \%$ and Spain $78.6 \%) .{ }^{29}$ This could have introduced bias into the study results.

Within the context of these limitations, we identified a number of disorders that cause a great deal of disability in Portugal. In general terms, non-communicable chronic diseases were responsible for the majority of DOR in the population, with digestive disorders, PTSD and bipolar disorders associated with the highest number of disability days at the individual level, followed by GAD and cancer. Although physical disorders had a greater than twofold higher prevalence than mental disorders, mental disorders were found to be among the most strongly associated with productivity loss in the Portuguese population. This finding is broadly consistent with previous studies in other populations ${ }^{38-40}$ as well as with the results of previous WMH Surveys in other countries. ${ }^{6}$ 
As comorbidity is so common, particularly among the mental disorders, the observed associations in studies prior to the WMH surveys, which failed to adjust adequately for comorbidity, could have been due not to the disorders themselves, but to their high comorbidities. This possibility was addressed here by controlling for comorbidity. This report is consistent with the results of the WMH Surveys in other countries ${ }^{6}$ in finding that mental disorders were among the most disabling disorders. Indeed, three of the five most disabling disorders at the individual level were mental disorders (PTSD, bipolar disorders and GAD), whereas the other two were physical disorders (digestive disorders and cancer).

The Portuguese sample results also showed a higher number of DOR across the majority of mental and physical disorders than the average across the 24 countries included in the WMH Surveys. This is particularly evident in Portugal's three more disabling disorders, where the annualised mean DOR were 63.5-66.2, compared with $41.2-42.9$ in the $24 \mathrm{WMH}$ countries overall sample. The median number of days totally out of role in the previous year was 77.9 in the Portuguese sample, whereas in the 24 countries sample the median was 51.1 days and in the higher income countries 52.3 days. Also, the mean number of DOR among respondents with positive DOR in Portugal was 157.0, whereas the corresponding numbers were 116.2 and $125.4 .^{6}$ All these figures indicate that disability associated with mental and physical disorders is particularly high in Portugal.

Our results show that the 18 health disorders considered in this study account for more than three-quarters of all DOR in the general Portuguese population studied ( $\mathrm{PARP}=78.2 \%$ ), with physical disorders accounting for $59.2 \%$ and mental disorders for $20.2 \%$. These numbers are higher than in the whole group of WMH Survey countries (PARP $=62.2 \%$ all disorders, $47.6 \%$ for physical and $16.5 \%$ for mental) and of high-income countries (PARP: 66.6, 52.7 and 16.0\%, respectively). It should be noted that the physical disorders include neurological disorders (epilepsy, multiple sclerosis and stroke), pain disorders (including severe headache/migraine) and insomnia. Among the physical disorders in the Portuguese population, cardiovascular disorders have the highest prevalence $(24.5 \%)$ and the highest societal impact on disability days because of this high prevalence despite not having one of the highest individual-level effects $(\mathrm{PARP}=30 \%)$ followed by arthritis, pain and headache/migraine (18.8, 13.6 and 10.0\%, respectively) (Table 4). PTSD, bipolar disorder, GAD and panic disorder, and the more frequent physical disorders should be prioritised to improve the productivity of the Portuguese society. Although PARPs indicate the theoretical proportion of outcome events that could be avoided if the exposure (the disorders in this study) was completely eliminated and are useful for identifying the burdensome targets for population intervention, it should be emphasised that disability days avoided by removing one disorder might limit the opportunity of avoiding the same days by removing another disorder. ${ }^{41}$

The present report shows a higher level of DOR both in mental and physical disorders compared with the means of other countries around the world and of high-income countries. A higher prevalence rate of mental disorders (any disorder lifetime $42.7 \%$, any disorder last year $22.9 \%$ and anxiety disorders last year $16.5 \%$ ) in the Portuguese population than in the other European countries has already been described elsewhere. ${ }^{8}$ This high prevalence is presumably responsible for at least some of the higher number of DOR in Portugal than other European countries. Other factors such as cultural, social and economic characteristics of the Portuguese society could modulate the association of disorders with DOR. All incapacitated workers are eligible for a sick leave pension, for both physical and mental disorders. The sick leave status must be confirmed by the worker's general practitioner or by a specialised doctor (http://www.seg-social.pt/subsidiode-doenca) Good accessibility to primary care services and the fact that being on sick leave carries little social stigma could be important explanatory factors.

Also, high time pressure and long working hours, together with relatively inflexible work schedules among Portuguese workers compared with their European counterparts (http://www.euro found.europa.eu/observatories/eurwork/comparative-information/ working-life-country-profiles), in association with low wages and low job satisfaction (http://www.oecdbetterlifeindex.org/countries/ portugal/), might well contribute to a higher level of professional stress with a possible impact on DOR.

The differences found in our study deserve further research, particularly now in a situation of financial and economic crisis in the country. Cross-national studies in employment strategies and DOR could help shed some light on this matter.

\section{Implications}

A first important implication of these findings is that the massive loss of productivity associated with the disorders considered here needs to be addressed in the Portuguese population. Further analysis of the data is needed to investigate patterns and correlates of delays in initially seeking treatment after first onset of the disorder, treatment dropout after initially obtaining treatment and treatment quality, all of which have been found in previous WMH analyses to be problems in the treatment of mental disorders. ${ }^{10,42}$ Programmes for early detection and intervention in the more common disorders, such as implementing collaborative care models between primary care and community mental health services, could address comorbidity, and reduce the persistence and severity of these disorders, and in this way reduce the number of DOR associated with these disorders.

Another implication involves our finding of persistent evidence of comorbidity and pervasive sub-additive interactions among comorbid disorders in predicting DOR. It is important to recognise that the latter result does not mean that comorbidity is not highly disabling. On the contrary, there is clear evidence that comorbidity is associated with high burden in terms of DOR. ${ }^{43}$ However, this disability increases at a decreasing rate when comorbid disorders exist. That is the interpretation of the subadditive interactions. The implication of this finding for the prevention of disability is that addressing only one disorder (treatment or prevention) when it coexists with other disorders will be less effective than addressing all the coexisting disorders, as the incremental effect of resolution of only one disorder in a comorbid set is low. ${ }^{44}$ This finding poses a serious challenge to the healthcare system to improve the currently low level of integration of treatment across disorders for the many people who suffer from multiple disorders, many of them including comorbidities of mental and physical disorders.

Graça Cardoso, MD, PhD, Chronic Diseases Research Centre (CEDOC), NOVA Medical School/Faculdade de Ciências Médicas, Universidade Nova de Lisboa, Lisboa, Portugal; Miguel Xavier, MD, PhD, Chronic Diseases Research Centre (CEDOC), NOVA Medical School/Faculdade de Ciências Médicas, Universidade Nova de Lisboa, Lisboa, Portugal; Gemma Vilagut, PhD, Health Services Research Unit, IMIM (Hospital del Mar Medical Research Institute), Barcelona, Spain; CIBER en Epidemiología y Salud Pública (CIBERESP), Madrid, Spain; Maria Petukhova, PhD, Department of Health Care Policy, Harvard Medical School, Boston, MA, USA; Jordi Alonso, MD, PhD, Health Services Research Unit, IMIM (Hospital del Mar Medical Research Institute), Barcelona, Spain; CIBER en Epidemiología y Salud Pública (CIBERESP), Madrid, Spain; Universitat Pompeu Fabra (UPF), Barcelona, Spain; Ronald C. Kessler, PhD, Department of Health Care Policy, Harvard Medical School, Boston, MA, USA; José Miguel Caldas-de-Almeida, $\mathrm{MD}, \mathrm{PhD}$, Chronic Diseases Research Centre (CEDOC), NOVA Medical School/ Faculdade de Ciências Médicas, Universidade Nova de Lisboa, Lisboa, Portugal

Correspondence: Graça Cardoso, Chronic Diseases Research Centre (CEDOC), NOVA Medical School/Faculdade de Ciências Médicas, Universidade Nova de Lisboa, Campo dos Mártires da Pátria, 130, 1169-056 Lisboa, Portugal. Email: gracacardoso@gmail.com

First received 4 Nov 2015, final revision 8 Jan 2017, accepted 15 Jan 2017 


\section{Acknowledgements}

We thank the staff of the WMH Data Collection and Data Analysis Coordination Centers for assistance with instrumentation, fieldwork and consultation on data analysis. None of the funders had any role in the design, analysis, interpretation of results, or preparation of this paper. A complete list of all within-country and cross-national WMH publications can be found at www.hcp.med.harvard.edu/wmh.

The analysis for this paper was carried out in conjunction with the World Health Organization WMH Survey Initiative. We thank the WMH staff and Ana Antunes, Daniel Neto, Diana Frasquilho and Helena Batista for assistance with data analysis. We also thank our funders for their valuable support.

\section{Funding}

The Portuguese Mental Health Study was carried out by the Department of Mental Health, NOVA Medical School, NOVA University of Lisbon, with collaboration of the CESOP - Portuguese Catholic University and was funded by the Champalimaud Foundation, the Gulbenkian Foundation, the Foundation for Science and Technology (FCT) and the Ministry of Health. The Portuguese Mental Health Study was carried out in conjunction with the World Health Organization WMH Survey Initiative which is supported by the National Institute of Mental Health (NIMH; R01 MH070884), the John D. and Catherine T. MacArthur Foundation, the Pfizer Foundation, the U.S. Public Health Service (R13-MH066849, R01-MH069864 and R01 DA016558), the Fogarty International Center (FIRCA R03-TW006481), the Pan American Health Organization, Eli Lilly and Company, OrthoMcNeil Pharmaceutical, GlaxoSmithKline and Bristol-Myers Squibb.

\section{References}

1 Davis K, Collins SR, Doty MM, Ho A, Holmgren A. Health and productivity among U.S. workers. Issue Brief (Commonwealth Fund) 2005; 856: 1-10.

2 Suhrcke M, Arce RA, McKee M, Rocco L. Economic Costs of III Health in the European region. European Observatory on Health Systems and Policies, World Health Organization, 2008

3 Merikangas KR, Ames M, Cui L, Stang PE, Ustun TB, Von Korff M, et al. The impact of comorbidity of mental and physical conditions on role disability in the US adult household population. Arch Gen Psychiatry 2007; 64: 1180-8.

4 Gustavsson A, Svensson M, Jacobi F, Allgulander C, Alonso J, Beghi E, et al. Cost of disorders of the brain in Europe 2010. Eur Neuropsychopharmacol 2011; 21: 718-79.

5 Stang PE, Brandenburg NA, Lane MC, Merikangas KR, Von Korff MR, Kessler RC. Mental and physical comorbid conditions and days in role among persons with arthritis. Psychosom Med 2006; 68: 152-8.

6 Alonso J, Petukhova MV, Vilagut G, Bromet EJ, Hintov H, Karam EG, et al. Days totally out of role associated with common mental and physical disorders. In The Burdens of Mental Disorders: Global Perspectives from the WHO World Mental Health Surveys (eds J. Alonso, S. Chatterji, Y. He): 137-48. Cambridge University Press, 2013.

7 Kessler RC, Ustun TB. The World Mental Health (WMH) Survey Initiative Version of the World Health Organization (WHO) Composite International Diagnostic Interview (CIDI). Int J Methods Psychiatr Res 2004; 13: 93-121.

8 Caldas-de-Almeida JM, Xavier M. Estudo Epidemiológico Nacional de Saúde Mental, 10 relatório [Portuguese Psychiatric Epidemiologic Study - First Report]. Faculdade de Ciências Médicas, 2013

9 Alonso J, Angermeyer MC, Bernert S, Bruffaerts R, Brugha TS, Bryson H, et al. Prevalence of mental disorders in Europe: results from the European Study of the Epidemiology of Mental Disorders (ESEMeD). Acta Psychiatr Scand Supp/ 2004; 420: 21-7.

10 Kessler RC, Aguilar-Gaxiola S, Alonso J, Chatterji S, Lee S, Ormel J, et al. The global burden of mental disorders: An update from the WHO World Mental Health (WMH) Surveys. Epidemiol Psichiatr Soc 2009; 18: 23-33.

11 World Bank. Data \& Statistics, Country Groups by Income, 2007 (http://data worldbank.org/about/country-classifications).

12 Instituto Nacional de Estatística. Censos 2011 - Resultados Provisorios. INE, 2011

13 Kessler RC, Üstün TB. The WHO World Mental Health Surveys: Global Perspectives on the Epidemiology of Mental Disorders. Cambridge University Press, 2008.

14 Heeringa SG, Wells JE, Frost H, Mneimneh ZN, Chiu GT, Sampson NA, et al. Sample designs and sampling procedures. In The WHO World Mental Health Surveys: Global Perspectives on the Epidemiology of Mental Disorders (eds RC Kessler, TB Üstün): 14-32. Cambridge University Press, 2008.

15 Xavier M, Baptista $H$, Mendes JM, Magalhães $P$, Caldas-de-Almeida JM. Implementing the World Mental Health Survey Initiative in Portugal - rationale, design and fieldwork procedures. Int J Ment Health Syst 2013; 7: 19

16 Pennell BE, Mneimneh ZN, Bowers A, Chardoul S, Wells JE, Viana MC, et al. Implementation of the World Mental Health Surveys. Chapter 3. Part I. Methods. In The WHO World Mental Health Surveys: Global Perspectives on the Epidemiology of Mental Disorders (eds RC Kessler, TB Üstün): 33-57. Cambridge University Press, 2008.

17 First MB, Spitzer RL, Gibbon M, Williams JBW. Structured Clinical Interview for DSM-IV Axis I Disorders, Research Version, Non-patient Edition (SCID-I/NP). Biometrics Research, New York State Psychiatric Institute, 2002.
18 Haro JM, Arbabzadeh-Bouchez S, Brugha TS, de Girolamo G, Guyer ME, Jin R, et al. Concordance of the composite international diagnostic interview version 3.0 (CIDI 3.0) with standardized clinical assessments in the WHO World Mental Health surveys. Int J Methods Psychiatr Res 2006; 15: 167-80.

19 Center for Disease Control and Prevention. Health, United States, 2004. US Government Printing Office, 2004.

20 Schoenborn CA, Adams PF, Schiller JS. Summary health statistics for the U.S. population: National Health Interview Survey, 2000. Vital Health Stat Rep Ser 10 2003; 214: 1-83

21 Knight M, Stewart-Brown S, Fletcher L. Estimating health needs: the impact of a checklist of conditions and quality of life measurement on health information derived from community surveys. J Public Health Med 2001; 23: 179-86.

22 Baker MM, Stabile M, Deri C. What Do Self-reported Objective Measures of Health Measure? National Bureau of Economic Research, 2001.

23 Von Korff M, Crane PK, Alonso J, Vilagut G, Angermeyer MC, Bruffaerts R, et al. Modified WHODAS-II provides valid measure of global disability but filter items increased skewness. J Clin Epidemiol 2008; 61: 1132-43.

24 World Health Organization. World Health Organization Disability Assessment Schedule II (WHODAS II). WHO, 2001.

25 Kessler RC, Ormel J, Demler O, Stang PE. Comorbid mental disorders account for the role impairment of commonly occurring chronic physical disorders: results from the National Comorbidity Survey. J Occup Environ Med 2003; 45: 1257-66.

26 Revicki DA, Irwin D, Reblando J, Simon GE. The accuracy of self-reported disability days. Med Care 1994; 32: 401-4.

27 Kessler RC, Ames M, Hymel PA, Loeppke R, McKenas DK, Richling DE, et al. Using the World Health Organization Health and Work Performance Questionnaire (HPQ) to evaluate the indirect workplace costs of illness. J Occup Environ Med 2004; 46: S23-37.

28 Gureje $O$. The pattern and nature of mental-physical comorbidity: specific or general? In Global Perspectives on Mental-Physical Comorbidity in the WHO World Mental Health Surveys (eds MR Von Korff, KM Scott, O Gureje): 51-83. Cambridge University Press, 2009.

29 Alonso J, Petukhova M, Vilagut G, Chatterji S, Heeringa S, Üstün TB, et al. Days out of role due to common physical and mental conditions: results from the WHO World Mental Health surveys. Mol Psychiatry. 2011; 16: 1234-46.

30 Seber GAF, Wild CL. Nonlinear Regression. Wiley, 1989

31 SAS Institute Inc. SAS Software Version 9.2. SAS Institute Inc., 2008.

32 Bates DM, Watts DG. Nonlinear Regression Analysis and its Applications. Wiley, 2007

33 Mccullagh P, Nelder JA. Generalized Linear Models. 2nd edn. Chapman \& Hall/ CRC, 1989.

34 Buntin MB, Zaslavsky AM. Too much ado about two-part models and transformation? Comparing methods of modeling Medicare expenditures. I Health Econ 2004; 23: 525-42.

35 Wolter K. Introduction to Variance Estimation. Springer-Verlag, 1985.

36 Gefeller O. An annotated bibliography on the attributable risk. Biom J 1992; 34 1007-12.

37 Sanderson $\mathrm{K}$, Andrews G. Common mental disorders in the workforce: recent findings from descriptive and social epidemiology. Can J Psychiatry 2006; 51: 63-75.

38 Polder JJ, Achterberg PW. Cost of IIIness in the Netherlands. National Institute for Public Health and the Environment, 2004.

39 Rice DP, Miller LS. Health economics and cost implications of anxiety and other mental disorders in the United States. Br J Psychiatry Supp/ 1998; 34: 4-9.

40 Smit F, Cuijpers P, Oostenbrink J, Batelaan N, de Graaf R, Beekman A. Costs of nine common mental disorders: implications for curative and preventive psychiatry. J Ment Health Policy Econ 2006; 9: 193-200.

41 Steenland $\mathrm{K}$, Armstrong B. An overview of methods for calculating the burden of disease due to specific risk factors. Epidemiology 2006; 17: 512-9.

42 Wang PS, Angermeyer M, Borges G, Bruffaerts R, Chiu WT, de Girolamo G, et al. Delay and failure in treatment seeking after first onset of mental disorders in the World Health Organization's World Mental Health Survey Initiative. World Psychiatry 2007; 6: 177-85.

43 Turner BJ, Hollenbeak CS, Weiner M, Ten Have T, Tang SS. Effect of unrelated comorbid conditions on hypertension management. Ann Intern Med 2008; 148 $578-86$.

44 Kessler RC, Avenevoli S, Costello EJ, Green JG, Gruber M, McLaughlin KA, et al. Severity of 12-month DSM-IV disorders in the National Comorbidity Survey Replication Adolescent Supplement. Arch Gen Psychiatry 2012; 69: 381-9. 